\title{
La (sobre)dimensión del crecimiento residencial en Madrid. El planeamiento urbanístico como coartada
}

\author{
Julio Vinuesa Angulo \\ Universidad Autónoma de Madrid. Departamento de Geografía \\ julio.vinuesa@uam.es
}

\author{
Blanca Martín Cortés ${ }^{1}$ \\ Geógrafa \\ bmartin@landuse.es
}

\section{Resumen}

Este trabajo centra la atención en analizar el papel que desempeña el análisis territorial en la elaboración de las propuestas de planeamiento. Se parte de la hipótesis de que, generalmente, carece de la calidad necesaria, está depreciado y es utilizado de forma interesada pero otorga un respaldo falsamente científico al planeamiento.

Para corroborarlo, se analizan las proyecciones demográficas y la cuantificación de viviendas propuestas por 19 planes generales de municipios de la Comunidad de Madrid. Los nuevos desarrollos urbanos ya producidos o propuestos en ellos no responden a criterios de racionalidad, equilibrio ni sostenibilidad territorial.

Novedoso por su preocupación por la mejora del tratamiento del análisis territorial y su correcta aplicación a las propuestas del planeamiento, este artículo se suma a la denuncia del modelo de desarrollo urbano y del papel que viene desempeñando el planeamiento, pero poniendo el foco en la crítica a la falta de rigor del análisis técnico como factor explicativo de la irracionalidad territorial.

Palabras clave: desarrollo urbano; crecimiento residencial; planeamiento urbanístico; Comunidad de Madrid; análisis demográfico aplicado.

Resum. La (sobre)dimensió del creixement residencial a Madrid. El planejament urbanistic com a coartada

Aquest treball centra l'atenció a analitzar el paper que té l'anàlisi territorial en l'elaboració de les propostes de planejament. Es parteix de la hipòtesi que, generalment, no té la qualitat necessària, es menysté i és utilitzada de manera interessada però dóna un suport falsament científic a la planificació.

Per tal de provar-ho, s'hi analitzen les projeccions demogràfiques i la quantificació d'habitatges proposats per dinou plans generals de municipis de la Comunitat de Madrid.

1. DEA en Territorio, Medioambiente y Sociedad (2009). Consultora en planificación urbanística y territorial. 
Els nous desenvolupaments urbans ja produïts o que s'hi proposen no responen a criteris de racionalitat, equilibri ni sostenibilitat territorial.

Innovador per la preocupació per la millora del tractament de l'anàlisi territorial i la correcta aplicació a les propostes del planejament, aquest treball s'afegeix a la denúncia del model de desenvolupament urbà i del paper que hi ha tingut el planejament, però posant el focus a la crítica en la manca de rigor de l'anàlisi tècnica com a factor explicatiu de la irracionalitat territorial.

Paraules clau: desenvolupament urbà; creixement residencial; planejament urbanístic; Comunitat de Madrid; anàlisi demogràfica aplicada.

Résumé. La (sur)dimension de la croissance résidentielle à Madrid. La planification urbaine comme alibi

Cette étude se concentre sur l'analyse du rôle de l'analyse territoriale dans l'élaboration de propositions de planification. À partir de l'hypothèse qu'il manque, généralement, la qualité nécessaire, est négligée et utilisé de façon intéressée, mais donne faussement appui scientifique à la planification.

Pour corroborer ça, s'analyse les projections démographiques et la quantification des logements proposés par 19 plans généraux de la Communauté de Madrid. Nouveaux développements proposés ou déjà produites ne répondent pas aux critères de rationalité, d'équilibre et de durabilité territoriale.

Ce travail, nouveau par la préoccupation dans l'amélioration du traitement de l'analyse spatiale et la bonne application des propositions d'aménagement s'ajoute à d'autres pour dénoncer le modèle de développement urbain et le rôle que la planification joue en se concentrant sur la critique de la manque de rigueur de l'analyse technique comme un facteur explicatif de l'irrationalité de cette planification.

Mots clé: développement urbain; croissance résidentielle; planification urbaine; Communauté de Madrid; analyse démographique appliquée.

\section{Abstract. The (over)Dimension of Residential Growth in Madrid: Urban planning as an Alibi}

This paper analyzes the role that territorial analysis plays in the decision-making processes of planning proposals. It assumes that such processes often lack rigor, are undervalued and used in a self-interested way, but offer false scientific evidence to support urban planning schemes.

To corroborate this statement, we analyze the demographic projections and quantification of housing stock proposed under the general urban development plans of 19 municipalities of the Community of Madrid. New urban developments or those proposed in these urban plans do not respond to criteria of rationality, balance or territorial sustainability.

This paper adds to the literature denouncing the urban development model and the role that urban planning is playing in it and makes a novel contribution for its concern about how to better apply territorial analysis in planning proposals. The paper highlights the lack of rigor of technical analyses as an explanatory factor of territorial irrationality.

Keywords: urban development; residential growth; urban planning; Region of Madrid; applied demographic analysis. 


\section{Sumario}

1. Planteamiento y justificación

2. Las dinámicas de los crecimientos observados y las propuestas de desarrollo inmobiliario

3. Los «análisis demográficos», pruebas irrefutables de la irracionalidad territorial
4. Consecuencias territoriales de la sobredimensión

5. Y ahora, ¿qué se puede hacer?

Referencias bibliográficas

\section{Planteamiento y justificación}

Con este trabajo, se busca seguir llamando la atención sobre la debilidad del análisis territorial como una de las deficiencias básicas del planeamiento urbanístico en España y, en particular, en la Comunidad de Madrid. La ausencia de estudios en esta línea, a excepción de las denuncias sobre la importancia del análisis geodemográfico en el planeamiento puestas de manifiesto por Vinuesa (1995), Burriel (2003) y Martín (2009) confieren «cierta» novedad al presente trabajo, al centrarse en el análisis de las deficiencias técnicas y metodológicas que presentan los 19 planes generales analizados en sus memorias de información y la falta de coherencia de las mismas con la realidad territorial.

Se considera que tampoco la geografía ha prestado la suficiente atención al desarrollo de los planteamientos conceptuales y metodológicos necesarios para una práctica más correcta del análisis territorial aplicada al planeamiento urbanístico. Ante la cada vez mayor prevalencia de los argumentos en favor del «desarrollismo» urbano a ultranza, es imprescindible poner en valor el análisis territorial como base racional en la que ha de sustentarse el planeamiento. Es preciso establecer un cambio de modelo que ayude a reconducir la voluntad política hacia el interés general, y éste solo puede sustentarse en la defensa de un uso más racional del territorio desde el conocimiento científico-técnico.

Se parte del hecho, fácilmente constatable, profusamente publicitado y generalmente criticado, de que, durante los tres últimos quinquenios, se han producido en España crecimientos residenciales muy por encima de las necesidades reales (Mata, 2008: 25; Burriel, 2008; Naredo et al., 2008: 56; Romero, 2010: 22). Antes de entrar en la valoración de los datos, conviene insistir en denunciar que la falta de información, de forma muy especial sobre el parque de vivienda y los flujos de hogares (Vinuesa et al., 2008: 83; Módenes, 2010: 120 ), sólo permite realizar aproximaciones a la realidad. Con datos de la EPA, se deduce un incremento de 3 millones de hogares para el periodo 2001-2009, en el que, según las estadísticas del Ministerio de Fomento, se construyeron 4,5 millones de viviendas. Según el censo de 2001, en España ya había 3,1 millones de viviendas vacías y los trabajos del censo de 2011 apuntan a que ahora podría haber 6 millones (Martínez, 2012). Tales dimensiones son difícilmente explicables, pues coincide un aumento en la construcción de vivienda con una demanda demográfica en declive y con una subida de precios. El exceso de producción inmobiliaria no es sino la intensificación de los efectos de un, ya 
antiguo pero plenamente vigente, modelo de desarrollo urbano arropado por una serie de ideas tan erróneas como fuertemente arraigadas en la sociedad: «el crecimiento urbano es siempre expresión del desarrollo económico y, por tanto, bueno por sí mismo y necesario", "cuantas más viviendas se construyan, mejor» o «el territorio sólo adquiere utilidad cuando está construido». Son distintas formas de expresar criterios, comúnmente aceptados, que se concretan en un modo de utilizar el territorio y de organizar el espacio urbano en el que la racionalidad y la sostenibilidad quedan preteridos ante el desarrollismo a ultranza y por las ambiciones y las expectativas de generar plusvalías.

Efectivamente, es difícilmente comprensible que, durante un decenio, se hayan construido varios millones más de las viviendas realmente necesarias para dar respuesta a la dinámica demográfica y que, generalmente, esos excesos se hayan producido bajo el amparo técnico y legal del planeamiento urbanístico. Pero no se debe olvidar que este proceso, que ha tenido una especial virulencia en el litoral mediterráneo y en las zonas de mayor dinamismo urbano, como la región metropolitana de Madrid (Rullán, 2011a: 280), siendo vinculable a factores económicos coyunturales, responde a un modelo de desarrollo urbano vigente en todas las regiones españolas desde hace decenios (Naredo, 2010).

La Ley del Suelo de 1956 institucionalizó el planeamiento urbanístico, que, de acuerdo con los principios neopositivistas recogidos en la Carta de Atenas, debería basarse en el conocimiento científico técnico de la realidad, como garantía de la aplicación de criterios de racionalidad territorial y sociodemográfica a la ordenación del crecimiento de las ciudades. Sin negar el carácter de acción política (voluntarista) que impulsa al planeamiento, siempre debería exigírsele racionalidad con respaldo científico técnico. Cabe preguntarse, entonces, qué tipo de argumentaciones se han utilizado en los planes para defender propuestas de desarrollo urbano tan exageradamente sobredimensionadas y tan alejadas de lo que respalda la teoría urbanística y propugnan los criterios de equidad, cohesión social y sostenibilidad.

Es preciso reconsiderar si el paroxismo en los excesos del dimensionamiento de los nuevos desarrollos residenciales, que puede identificarse mediante la simplificación de «burbuja inmobiliaria» (Rullán, 2007), es un suceso excepcional. Aunque se quiera ver en la coyuntura financiera su desencadenante fundamental, hay que reconocer que ésta no ha tenido los mismos efectos en todos los países. En España hay componentes económicos, legislativos, políticos, urbanísticos (Gaja, 2008: 109), sociales y culturales (Martín, 2012: 28), con una larga tradición. Y, sobre todo, la falta de rigor científico técnico en el planeamiento urbanístico y la ausencia de capacidad evaluadora de la sociedad son elementos determinantes de todo el entramado.

Se parte de la hipótesis de que la incoherencia consumada ha sido posible por una sistemática y progresiva desvalorización del análisis territorial en la planificación urbana (Martín, 2012: 12) bajo un marco legislativo que resulta rígido y obsoleto y que constriñe los procesos de redacción del planeamiento, así como por la inexistencia de planificación territorial que regule el crecimiento local a partir de criterios supralocales (Burriel, 2008: 35). En síntesis, que las 
Tabla 1. Población de los municipios de la Comunidad de Madrid con planes generales aprobados entre 2000 y 2011

\begin{tabular}{|c|c|c|c|c|c|c|c|}
\hline \multirow[b]{2}{*}{ Municipio } & \multirow[b]{2}{*}{$\begin{array}{l}\text { Año de } \\
\text { aprobación } \\
\text { del PGOU }\end{array}$} & \multicolumn{4}{|c|}{ Residentes } & \multicolumn{2}{|c|}{ Crecimiento 2000-2011 } \\
\hline & & 2000 & 2005 & 2011 & $\begin{array}{l}\text { En el } \\
\text { año de la } \\
\text { aprobación }\end{array}$ & Habitantes & TAA (\%) \\
\hline Móstoles & 2009 & 196.289 & 204.463 & 205.015 & 206.478 & 8.726 & 0,4 \\
\hline Getafe & 2003 & 146.310 & 157.397 & 170.115 & 156.315 & 23.805 & 1,4 \\
\hline Alcobendas & 2009 & 89.612 & 103.149 & 109.705 & 109.104 & 20.093 & 1,9 \\
\hline Pozuelo de Alarcón & 2002 & 66.298 & 78.083 & 82.916 & 71.246 & 16.618 & 2,1 \\
\hline Rivas-Vaciamadrid & 2004 & 29.092 & 49.696 & 72.896 & 45.099 & 43.804 & 8,7 \\
\hline Valdemoro & 2004 & 28.243 & 44.136 & 68.418 & 40.839 & 40.175 & 8,4 \\
\hline Boadilla del Monte & 2002 & 20.686 & 35.588 & 46.151 & 27.145 & 25.465 & 7,6 \\
\hline $\begin{array}{l}\text { San Fernando } \\
\text { de Henares }\end{array}$ & 2002 & 32.364 & 39.966 & 41.380 & 36.658 & 9.016 & 2,3 \\
\hline Tres Cantos & 2003 & 35.046 & 39.198 & 41.065 & 38.804 & 6.019 & 1,5 \\
\hline Navalcarnero & 2009 & 13.522 & 17.183 & 24.613 & 21.584 & 11.091 & 5,6 \\
\hline Ciempozuelos & 2008 & 13.564 & 17.769 & 23.354 & 21.256 & 9.790 & 5,1 \\
\hline $\begin{array}{l}\text { Paracuellos del } \\
\text { Jarama }\end{array}$ & 2001 & 5.889 & 7.568 & 18.482 & 6.334 & 12.593 & 11,0 \\
\hline Meco & 2009 & 6.328 & 10.774 & 12.554 & 12.419 & 6.226 & 6,4 \\
\hline Brunete & 2008 & 5.080 & 8.096 & 9.967 & 9.275 & 4.887 & 6,3 \\
\hline El Álamo & 2008 & 4.676 & 6.613 & 8.475 & 7.580 & 3.799 & 5,6 \\
\hline $\begin{array}{l}\text { Fuente el Saz } \\
\text { de Jarama }\end{array}$ & 2010 & 4.004 & 5.605 & 6.377 & 6.320 & 2.373 & 4,3 \\
\hline Serranillos del Valle & 2006 & 923 & 2.787 & 3.515 & 3.006 & 2.592 & 12,9 \\
\hline Casarrubuelos & 2007 & 731 & 2.141 & 3.224 & 2.894 & 2.493 & 14,4 \\
\hline Fresno de Torote & 2006 & 643 & 1.483 & 2.041 & 1.611 & 1.398 & 11,1 \\
\hline
\end{tabular}

Fuente: elaboración propia a partir de datos de la Consejería de Medio Ambiente y Ordenación del Territorio y del Instituto de Estadística de la Comunidad de Madrid.

expectativas generadas por la dinámica del mercado constituyen el argumento determinante frente a los posibles criterios científico-técnicos.

Para corroborar esta hipótesis de trabajo, se ha procedido al análisis de la documentación de los 19 planes generales ${ }^{2}$ de municipios de la Comunidad de Madrid, con aprobación definitiva entre los años 2000 y 2011 (tabla 1), lo que ha permitido constatar que el planeamiento urbanístico se ha convertido básicamente en una herramienta al servicio de los planteamientos que identifican urbanización con desarrollo económico (Brandis, 2008: 3); que los

2. Información consultada a través de la página web de la Consejería de Medio Ambiente y Ordenación del Territorio de la Comunidad de Madrid. 
contenidos técnicos, que teóricamente habrían de ser garantes de la coherencia territorial entre la dinámica demográfica y el desarrollo espacial, son un cúmulo de sofismas que, en ausencia de un control superior y riguroso, se convierten en cómplices de los intereses económicos para enmascarar el uso irracional que el planeamiento hace del territorio.

El criterio para la selección de planes tomados como ejemplo ha sido la fecha de aprobación definitiva, porque se ha considerado que los planes más recientes (más modernos) han de ser más ilustrativos a la hora de valorar la experiencia planificadora y porque la aprobación definitiva incorpora posibles modificaciones derivadas de la consulta pública e interadministrativa. Se trata de municipios muy heterogéneos en cuanto a su superficie, al tamaño de su población, a la dinámica demográfica, a la estructura sociourbanística y a la localización con respecto a Madrid o al partido político gobernante (figura 1).

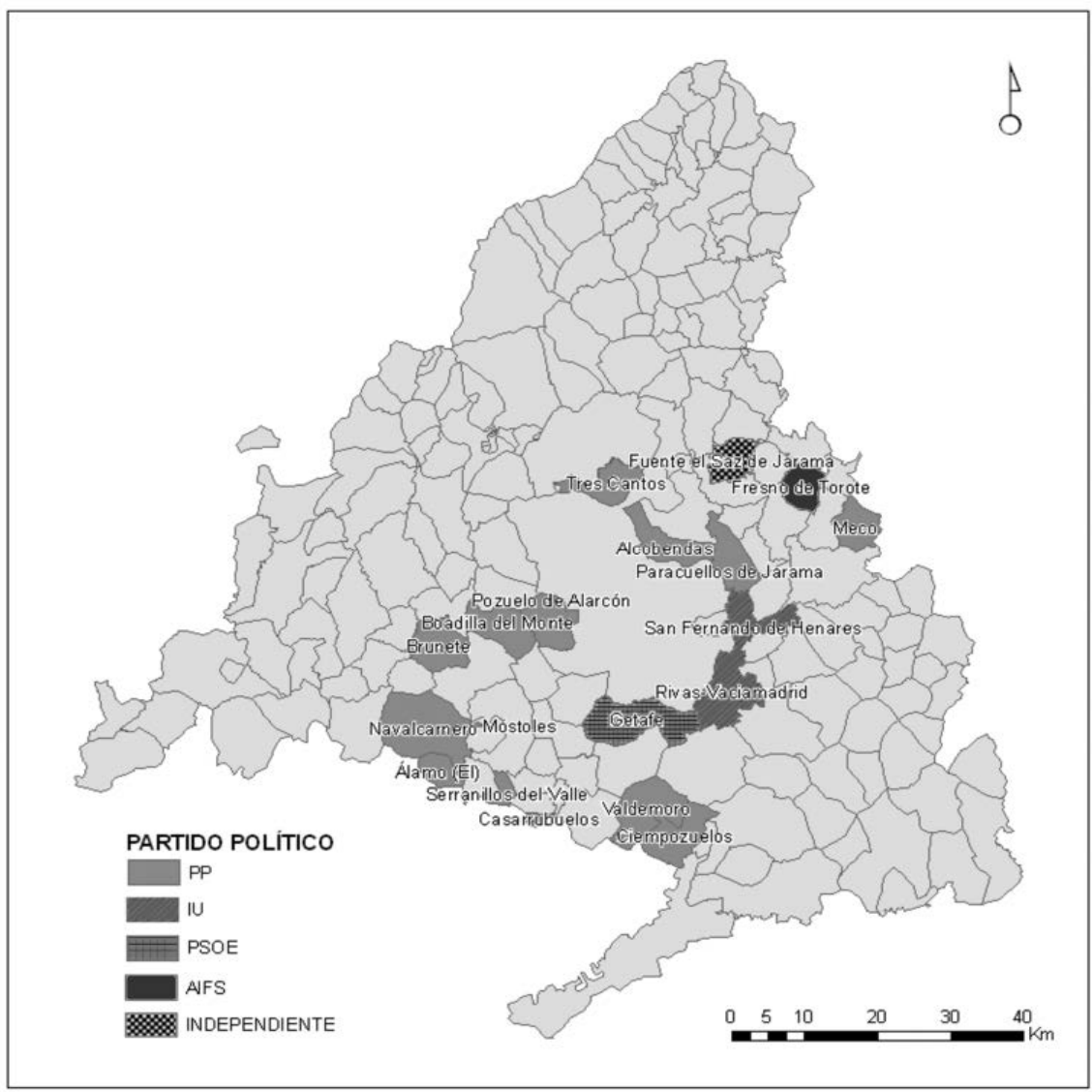

Figura 1. Localización de los municipios con PGOU aprobado entre 2001 y 2011. Fuente: elaboración propia. 
Esa diversidad es también considerada, en principio, como un elemento a favor de la representatividad de los resultados que se obtienen. Por el contrario, el hecho de que el análisis se circunscriba al espacio metropolitano madrileño aconseja matizar la extensión de las conclusiones a otros ámbitos con menor presión inmobiliaria.

El análisis realizado permite cuantificar el suelo residencial aprobado y el número de viviendas propuesto en cada caso, para ponerlos en relación con las previsiones demográficas que se incorporan como soporte o justificación técnica. Se trata también de valorar la solidez de los análisis y de las proyecciones demográficas.

\section{Las dinámicas de los crecimientos observados y las propuestas de desarrollo inmobiliario}

Entre los municipios seleccionados para el análisis del planeamiento, hay una gran variedad de tamaños y de ritmos de crecimiento (tabla 1), que básicamente responden a su cronología en el proceso de metropolitanización. La ordenación según el volumen de residentes en 2011 permite apreciar una importante correlación inversa entre tamaño y ritmos de crecimiento. Los que presentan mayores ritmos de crecimiento son los municipios más alejados de la capital y de desarrollo más reciente.

La revisión del planeamiento, con el pretexto de atender una teórica demanda de suelo residencial y para actividades económicas, es el instrumento clave para la reclasificación de suelo. Con la aprobación de los planes estudiados, se ha producido una reclasificación de suelo urbanizable de 195 millones de metros cuadrados (tabla 2), que supone duplicar la superficie ocupada por el suelo urbano existente. 61,9 millones de metros cuadrados están calificados como suelo residencial sectorizado, en previsible ejecución inmediata y 80,3 millones, como suelo urbanizable no sectorizado. En conjunto, estos planes permiten construir casi 145.000 viviendas (tabla 3), que, utilizando el tamaño medio del hogar del censo de 2001 para la Comunidad de Madrid $(2,88)$, supondría una capacidad de acogida de unos 416.000 residentes más.

Sin embargo, las últimas proyecciones del INE prevén, para el decenio 2011-2021, un crecimiento de tan sólo 24.575 habitantes en el conjunto de la Comunidad (INE, 2011), lo que, traducido a hogares, equivale al $5,9 \%$ de las viviendas previstas en tan sólo 19 de los 179 municipios del territorio regional. Se podría argumentar que el crecimiento acumulado por estos municipios se producirá a costa de la población de otros, hipótesis que habría que desechar conociendo sus previsiones igualmente expansivas. Los diferentes planes defienden "técnicamente», desde una óptica exclusivamente local, grandes crecimientos exógenos, pero, al ampliar el ámbito de análisis a la provincia, se demuestran absurdos, y más aún si se considera que también en las provincias limítrofes hay previstos importantes crecimientos (Illescas y Seseña en Toledo y Valdeluz en Guadalajara son los casos más llamati- 
Tabla 2. Propuestas de crecimiento de suelo urbanizable de los planes generales

\begin{tabular}{|c|c|c|c|c|c|c|c|c|c|}
\hline & & & & & elo urbanizab & le $\left(000 \mathrm{~m}^{2}\right)^{*}$ & & & Incremento \\
\hline & & Suelo & & & Sectorizad & & & Suelo no & residencial \\
\hline & $\left(\mathrm{Km}^{2}\right)$ & $\left(000 \mathrm{~m}^{2}\right)$ & Total & Total & Residencial & Productivo & sectorizado & $\left(000 \mathrm{~m}^{2}\right)$ & sobre suelo urbano \\
\hline El Álamo & 22 & 2.609 & 3.712 & 1.583 & 1.207 & 326 & 1.641 & 16.059 & 1,46 \\
\hline Alcobendas & 45 & 18.802 & 7.720 & 3.226 & 2.151 & 1.075 & 4.494 & 17.590 & 1,11 \\
\hline Boadilla del Monte & 47 & 17.385 & 13.358 & 13.358 & 4.371 & 2.321 & 0 & 16.502 .191 & 1,25 \\
\hline Brunete & 49 & 1.980 & 13.670 & 8.824 & 7.426 & 1.398 & 4.850 & 33.250 & 4,75 \\
\hline Casarrubuelos & 6 & 869 & 1.457 & 898 & 216 & 0 & 559 & 5.340 & 1,25 \\
\hline Ciempozuelos & 45 & 3.253 & 9.825 & 5.901 & 3.812 & 2.289 & 1.560 & 36.296 & 2,17 \\
\hline Fresno de Torote & 32 & 2.640 & 2.099 & 2.099 & 2.099 & 0 & 0 & 26.911 & 1,80 \\
\hline Fuente el Saz & 33 & 2.302 & 5.086 & 4.171 & 1.804 & 2.260 & 915 & 25.761 & 1,78 \\
\hline Getafe & 79 & 18.948 & 25.640 & 10.107 & 4.637 & 4.973 & 15.533 & 34.152 & 1,24 \\
\hline Meco & 35 & 4.465 & 11.529 & 6.784 & 4.445 & 1.930 & 4.745 & 18.942 & 2,00 \\
\hline Móstoles & 45 & 13.457 & 14.409 & 9.511 & 2.249 & 3.154 & 4.899 & 13.424 & 1,17 \\
\hline Navalcarnero & 100 & 5.599 & 29.383 & 13.805 & 12.331 & 0 & 15.578 & 65.802 & 3,20 \\
\hline Paracuellos & 44 & 3.840 & 7.890 & 4.522 & 2.828 & 1.694 & 3.368 & 31.770 & 1,74 \\
\hline Pozuelo de Alarcón & 43 & 33.297 & 6.160 & 6.160 & 6.160 & 0 & 0 & 3.783 & 1,19 \\
\hline Rivas & 67 & $N / D$ & 5.802 & 5.802 & 3.112 & 269 & 0 & 47.710 & $\mathrm{~N} / \mathrm{D}$ \\
\hline $\begin{array}{l}\text { San Fernando } \\
\text { de Henares }\end{array}$ & 39 & 4.491 & 5.807 & 5.295 & N/D & 5.295 & 511 & 25.810 & $\mathrm{~N} / \mathrm{D}$ \\
\hline Serranillos del Valle & 13 & 13.340 & 2.295 & 1.117 & $N / D$ & 0 & 1.178 & 9.796 & $\mathrm{~N} / \mathrm{D}$ \\
\hline Tres Cantos & 38 & $N / D$ & 3.739 & 3.290 & 767 & 948 & 449 & N/D & $\mathrm{N} / \mathrm{D}$ \\
\hline Valdemoro & 64 & 11.896 & 25.570 & 5.564 & 2.270 & 3.255 & 20.006 & 26.734 & 1,19 \\
\hline Totales & 846 & 159.175 & 195.149 & 112.017 & 61.920 & 31.187 & 80.285 & 16.941 .320 & 1,39 \\
\hline
\end{tabular}

* En algunos planes no cuadran los totales de suelo urbanizable por las diferencias de criterios a la hora de cuantificar e imputar las superficies de sistemas generales.

Fuente: elaboración propia a partir de datos de la Consejería de Medio Ambiente y Ordenación del Territorio y del Instituto de Estadística de la Comunidad de Madrid. Documento de aprobación de los planes publicado en el BOCM.

vos) justificados sólo por la «previsible» llegada de residentes desde el centro metropolitano.

La capacidad edificatoria para el conjunto de estos 19 municipios supone el $51 \%$ del parque de vivienda existente en 2001 (tabla 3), pero en algunos casos se proponen crecimientos de vivienda que cuadruplican (Fresno de Torote) o duplican (Brunete, Casarrubuelos, Paracuellos) ampliamente el número de viviendas existentes.

Durante los años 2001 a 2010, el parque residencial de la Comunidad de Madrid se ha incrementado en 480.030 viviendas (Ministerio de Fomento, 
Tabla 3. Viviendas previstas y crecimiento del parque inmobiliario respecto al censo de 2001

\begin{tabular}{|c|c|c|c|}
\hline & $\begin{array}{l}\text { Viviendas } \\
\text { previstas }\end{array}$ & $\begin{array}{l}\text { Viviendas } \\
\text { censo } 2001\end{array}$ & $\begin{array}{l}\text { Incremento de viviendas previstas } \\
\text { sobre viviendas censo } 2001(\%)\end{array}$ \\
\hline El Álamo & 2.385 & 3.367 & $71 \%$ \\
\hline Alcobendas & 8.600 & 31.999 & $27 \%$ \\
\hline Boadilla del Monte & 8.734 & 11.218 & $78 \%$ \\
\hline Brunete & 8.600 & 3.711 & $232 \%$ \\
\hline Casarrubuelos & 1.118 & 545 & $205 \%$ \\
\hline Ciempozuelos & 8.000 & 6.342 & $126 \%$ \\
\hline Fresno de Torote & 3.395 & 869 & $391 \%$ \\
\hline Fuente el Saz & 3.711 & 2.674 & $139 \%$ \\
\hline Getafe & 17.180 & 56.872 & $30 \%$ \\
\hline Meco & 6.770 & 3.813 & $178 \%$ \\
\hline Móstoles & 13.340 & 72.132 & $18 \%$ \\
\hline Navalcarnero & 5.165 & 6.847 & $75 \%$ \\
\hline Paracuellos & 6.400 & 2.919 & $219 \%$ \\
\hline Pozuelo de Alarcón & 13.529 & 24.404 & $55 \%$ \\
\hline Rivas & 13.293 & 12.731 & $104 \%$ \\
\hline San Fernando de Henares & 0 & 14.713 & $\mathrm{~N} / \mathrm{D}$ \\
\hline Serranillos del Valle & 1.431 & 1.190 & $120 \%$ \\
\hline Tres Cantos & 5.775 & 13.210 & $44 \%$ \\
\hline Valdemoro & 14.767 & 14.160 & $104 \%$ \\
\hline Totales & 144.472 & 283.716 & $51 \%$ \\
\hline
\end{tabular}

Fuente: elaboración propia a partir de datos de la Consejería de Medio Ambiente y Ordenación del Territorio y del Instituto de Estadística de la Comunidad de Madrid. Documento de aprobación de los planes publicado en el BOCM y censo de 2001.

2012), a un ritmo medio anual de 8,2 por cada 1.000 habitantes, con un máximo de 12,2 en 2004 y un mínimo de 4,4 en 2010, ya confirmado el pinchazo de la burbuja. Son intensidades medias próximas al doble de lo que se considera normal para atender la demanda endógena (5 nuevas viviendas al año por cada 1.000 habitantes), pero inferiores a los ritmos establecidos en los planes estudiados, que, básicamente, se articulan sobre unas previsiones de demanda exógena, escasa o erróneamente fundamentadas, en las que, en buena parte de los casos, se confunden los deseos con la realidad.

El PGOU de Fresno de Torote, aprobado en 2006, clasifica 2 millones de metros cuadrados de suelo urbanizable residencial, todo sectorizado, con capacidad para 3.395 nuevas viviendas, lo que permitiría multiplicar por seis su población inicial. La revisión del PGOU de Brunete, aprobado en 2008, 
clasifica casi 7,5 millones de metros cuadrados sectorizados para uso residencial en el que se podrían edificar unas 8.600 viviendas que permitirían multiplicar su población casi por tres.

El caso de Paracuellos, con un PGOU aprobado en 2001, en pleno despegue del boom inmobiliario, puede servir como ejemplo de hasta qué punto el plan justifica unos desarrollos urbanísticos sin conexión con las dinámicas endógenas. Se ha pasado de 6.334 habitantes en el momento de la aprobación del plan a 18.482 en enero de 2011 como consecuencia del desarrollo de la urbanización Miramadrid, localizada a unos 3 kilómetros del núcleo tradicional y que incorpora 4,5 millones de metros cuadrados urbanizables sectorizados, con capacidad para 6.400 nuevas viviendas. Pero si se desarrollase el suelo urbanizable no sectorizado (ampliación de Miramadrid 2), se podría llegar a 40.000 habitantes. Las dimensiones recogidas en las tablas 2 y 3 permiten apreciar que los excesos a la hora de clasificar suelo urbanizable y programar nueva capacidad residencial son la norma.

Pero no sólo hay que fijarse en lo inverosímil de los incrementos de vivienda y de población previstos, también hay que prestar atención al consumo de suelo que suponen. Son numerosos los planes que se proponen agotar la capacidad municipal de crecimiento. Boadilla ${ }^{3}$, Fresno de Torote ${ }^{4}$, Pozuelo $^{5}$, Rivas ${ }^{6}$, Tres Cantos $^{7}$ y San Fernando de Henares ${ }^{8}$ clasifican todo el suelo no sometido a protección especial como urbanizable sectorizado, con la única restricción de las limitaciones medioambientales. Brunete ${ }^{9}$, Alcobendas $^{10}$, Ciempozuelos ${ }^{11}$, Getafe ${ }^{12}$, Meco ${ }^{13}$, Móstoles ${ }^{14}$, Valdemoro ${ }^{15}$ y Serrani$1 \operatorname{los}^{16}$ hacen lo mismo, pero reservan suelos urbanizables no sectorizados para futuros desarrollos. Casarrubuelos, El Álamo, Fuente el Saz, Navalcarnero y Paracuellos incluyen, en su modelo de ordenación, suelos de protección no específica, pero en todo caso con altísimas ocupaciones del territorio. Todo ello corrobora que estamos ante un modelo que valora proteger o conservar sólo algunos enclaves específicos y únicamente por imposición de la normativa sectorial.

3. Acuerdo de aprobación del PGOU de Boadilla del Monte. BOCM, n. ${ }^{\circ} 45,22 / 01 / 2002$, p. 30.

4. Acuerdo de aprobación. BOCM, n. ${ }^{o}$ 262, 03/11/2006, p. 42.

5. Texto refundido de la memoria de aprobación definitiva, p. 36 y 57.

6. Acuerdo de aprobación. BOCM, n. ${ }^{\circ}$ 95, 22/04/2004, p. 17.

7. Acuerdo de aprobación. BOCM, n. ${ }^{\circ}$ 156, 2/06/2003, p. 21.

8. Acuerdo de aprobación. BOCM, n. ${ }^{\circ} 236,4 / 10 / 2002$, p. 43.

9. Acuerdo de aprobación. BOCM, n.o 49, 27/02/2008, p. 37.

10. Acuerdo de aprobación. BOCM, n. ${ }^{\circ} 173,23 / 07 / 2009$, p. 28.

11. Acuerdo de aprobación. BOCM, n. ${ }^{\circ}$ 180, 30/07/2008, p. 257.

12. Memoria del PGOU de Getafe (2002), p. 184 y 195.

13. Acuerdo de aprobación. BOCM, n. ${ }^{\circ} 251,22 / 10 / 2009$, p. 35 y 36.

14. Acuerdo de aprobación. BOCM, n. ${ }^{\circ} 81,6 / 04 / 2009$, p. 36.

15. Acuerdo de aprobación. BOCM, n. ${ }^{\circ}$ 118, 19/05/2004, p. 12.

16. Plano de clasificación [en línea]. <http://www.madrid.org/cartografia/planea/planeamiento/ $\mathrm{html} / \mathrm{web} /$ Visor Planeamiento.htm> [Consulta: diciembre 2011]. 


\section{Los «análisis demográficos», pruebas irrefutables de la irracionalidad territorial}

Las cifras de población, por su disponibilidad y la aparente obviedad de su significado, son comúnmente utilizadas como principales, cuando no únicos, referentes de la dinámica socioeconómica. La normativa que regula la elaboración de los planes urbanísticos en la Comunidad de Madrid hace referencia al estudio de las «características de la población asentada sobre el territorio, sus condiciones económicas y sociales y las previsiones de su evolución ${ }^{17}$ para la justificación del modelo territorial. No es necesario profundizar aquí sobre las limitaciones técnicas de la normativa existente (Vinuesa, 1995: 154; Burriel, 2002: 444; Burriel, 2003: 93; Martín, 2012) para denunciar, con pruebas concluyentes de planes, momentos y municipios concretos, la ausencia de la más elemental coherencia metodológica y de rigor técnico en el planeamiento urbanístico. Se entiende que la documentación de los municipios madrileños objeto de valoración es representativa de gran parte del planeamiento que se viene realizando en España, según apuntan los resultados provisionales de una investigación más amplia en proceso y, sobre todo, de los criterios normalmente seguidos para dimensionar los desarrollos urbanos y, como se podrá apreciar, valida de manera difícilmente refutable las tesis aquí defendidas sobre la torticera utilización del planeamiento.

Una interpretación de las derivaciones metodológicas de la normativa legal nos lleva a considerar dos posibles planteamientos antagónicos. El primero aparece con la exigencia de la Ley del Suelo de 1956, al establecer que la cantidad del suelo necesario, clasificable para el futuro desarrollo urbano, habrá de justificarse a partir de las estimaciones de crecimiento de la población y, tal como concreta el Reglamento de Planeamiento de 1978, las actuaciones correspondientes habrían de programarse en dos cuatrienios. Podría decirse que, en el espíritu de la legislación urbanística, la dinámica demográfica observada debía ser considerada como una variable independiente y su proyección, como el factor determinante de la superficie residencial y del número de viviendas necesarias.

La Ley 7/1997, de 14 de abril, de medidas liberalizadoras en materia de suelo y la Ley de 13 abril de 1998, sobre régimen de suelo y valoraciones, producen un giro copernicano al establecer, como principal expresión de su impulso liberalizador, que, salvo el suelo urbano y aquel otro con algún tipo de protección legal, todo el territorio municipal restante es urbanizable. Desaparece, además, el suelo urbanizable programado y, con él, la exigencia de establecer un marco temporal a las previsiones del plan. El cambio conceptual del suelo urbanizable supone la desaparición del mandato explícito de tener que justificar la necesidad del suelo que el plan clasifica. Ahora bien, el disponer de mayor libertad para planificar no debería entenderse como la potestad

17. Artículo 38 del Real Decreto 2159/1978, por el que se aprueba el Reglamento de Planeamiento de la Ley de 1976, que es trasladado al desarrollo reglamentario autonómico sin prácticamente modificación alguna. 
para prescindir de la racionalidad, en principio consustancial a la planificación urbana (Vinuesa, 2003: 285; Burriel, 2003: 448; Vinuesa, 2005: 262).

Aunque se suele culpar a ese cambio legislativo de ser el desencadenante de la última "burbuja inmobiliaria», más bien se trata sólo de un notable factor coadyuvante, pues la primera causa está, como ha señalado Onofre Rullán (2011a), en la «disponibilidad financiera». En esencia, el «disparate financiero-inmobiliario» que, con intensidad inusitada, se prolonga durante casi una década, no hubiera sido muy diferente con la legislación anterior y tampoco mucho menores sus efectos sobre el territorio. Hasta la de 2007, todas las leyes del suelo se han articulado en torno a la creencia de que la carestía del suelo deriva de su escasez (Rullán, 2007).

En la práctica no ha sido así, pero el marco normativo creado a partir de 1996 ofrece la posibilidad de una mayor coherencia metodológica. Por una parte, se elimina el error conceptual de las leyes anteriores que lleva a considerar a la dinámica demográfica como una variable independiente (Vinuesa, 1995: 155; Reques, 2003: 220). Por otra parte, con el nuevo planteamiento liberal, nada exime de tener que justificar ante la sociedad la coherencia del modelo territorial con los principios que se propugnen y mediante análisis técnicos rigurosos, aunque las determinaciones del plan sean consecuencia de la voluntad política legítimamente ejercida.

Los «análisis demográficos» de los planes que se valoran a continuación tienen enfoques y contenidos diversos que dificultan una valoración sistemática de los mismos. Es común, sin embargo, su intencionalidad, más o menos explícita, de «demostrar» la necesidad o la conveniencia de provocar enormes crecimientos residenciales. Y ello es así incluso en los planes cuya aprobación es posterior a 2007. Son también comunes las inconsistencias técnicas, especialmente en las proyecciones de población, cuando existen, y las incongruencias de las argumentaciones.

Es paradigmático, por su simplicidad en la falacia argumental, el Plan de El Álamo, en el que, tras describir, a través de los crecimientos de población, el fenómeno de expansión metropolitana hacia la comarca del sudoeste de Madrid, se afirma que está constatado que el crecimiento de población «está relacionado con el aumento de las viviendas ${ }^{18}$ ». La argumentación es que, con el nuevo plan, se podrían construir 2.000 nuevas viviendas, por lo que habría 6.000 habitantes más. Como la población va a crecer en 6.000 habitantes, será necesario construir 2.000 viviendas nuevas, propuesta que el plan acaba estableciendo como uno de los «objetivos específicos» en el apartado "vivienda» ${ }^{19}$. Por absurda que pueda parecer, esa es la argumentación que, en esencia, aunque en diferentes versiones más elaboradas, se repetirá en la mayor parte de los planes.

En el Plan de Alcobendas, se dedica un apartado a «Proyecciones de población» ${ }^{20}$, que contiene unas extrapolaciones elaboradas con las tasas de creci-

18. Documento de aprobación provisional. Memoria de información, ap. 3.2, p. 34.

19. Memoria de información, ap. 1.3.2, p. 84.

20. Memoria de aprobación provisional, p. 19-21. 
miento observadas en tres periodos distintos (2007-2008: 1,47\%, 2003-2008: 1,85\% y 2004-2005: 2,83\%). Los resultados, descalificables entre otras razones por la simplicidad del método, sirven para establecer, a partir de la «hipótesis» más alta, el número de viviendas necesarias. Sin datos objetivos que los respalden, se utilizan distintos argumentos sobre la población que está ocupando o que va a ocupar las 8.348 viviendas que ya estaban desarrollándose en el municipio. Todo ello con el propósito de justificar, básicamente con la misma lógica que en El Álamo, que es necesario clasificar más suelo. En un municipio de gran entidad urbana, unas simples y más que discutibles extrapolaciones, realizadas sin ningún rigor técnico, pasan por ser unas estimaciones de crecimiento «en función de los análisis demográficos» (?) que determinan la necesidad de clasificar suelo para otras 11.000 viviendas.

En algunos casos $\left(\mathrm{Meco}^{21}\right.$, Boadilla ${ }^{22}$, Brunete ${ }^{23}$, etc.), aparece una interpretación maximalista de la Ley de 1998: si todo el suelo es urbanizable, hagamos lo necesario para que se construya. Se suele argumentar que la proximidad del desarrollo metropolitano de Madrid garantiza que todo acabará "colmatándose» y se utiliza como ejemplo «el planeamiento de Madrid Capital, que ha establecido su redacción del Plan General como cierre de la ordenación urbana de su término municipal».

En el Plan de Brunete, se expone claramente el planteamiento expansionista:

[...] dada la peculiar situación de «abandono o vacío» de actividad urbanística en los últimos 20 años, el Equipo de Gobierno consideró oportuno y conveniente producir una fuerte oferta de suelo urbanizable [...] que otorgase a Brunete la competitividad territorial a la que su localización le vocaciona ${ }^{24}$.

El hecho de que este plan se aprobara en 2008, explica quizás el papel restrictivo y racionalizador ejercido en este caso por el Consejo de Gobierno de la Comunidad de Madrid, tal como se recoge en el Acuerdo de Aprobación:

[...] la propuesta municipal tiene que compatibilizarse y converger con las previsiones, planes y programas de la Comunidad de Madrid, permitiendo el uso racional del suelo y de la vivienda [...] en relación con los criterios supralocales de desarrollo ordenado y sostenible [...] por lo que el PGOU habrá de ajustarse a unos parámetros más ajustados a las circunstancias actuales del entorno metropolitano [...] reduciendo el número de viviendas en un $30 \%$, estableciendo plazos de ejecución sucesivos, priorizando la vivienda pública, disminuyendo la edificabilidad residencial ${ }^{25}$.

21. "Criterios y objetivos de ordenación del modelo de ciudad propuesta». Memoria de ordenación, ap. 1.3 , p. 83 y siguientes.

22. «Situación urbana futura», 3.2, p. 49 y «Modelo territorial propuesto», 3.3, p. 52.

23. El Plan General, un proyecto de futuro, 2.4, p. 61.

24. Memoria de aprobación definitiva, p. 824-829.

25. Acuerdo de aprobación. BOCM, n. ${ }^{\circ}$ 49, 27/02/2008, p. 37. 
En Navalcarnero, tras cuestionar el grado de fiabilidad de las proyecciones, se extrapola la "tasa media de crecimiento» ${ }^{26}(5,35 \%)$ de los últimos diecisiete años hasta el 2027 y se obtiene una población de 53.000 habitantes. Además de la simplicidad del procedimiento y la inconsistencia argumental a la hora de prever el futuro, la tasa utilizada no es real. Pero al dato obtenido se aplica un «índice de ocupación del censo municipal de 3,15 hab/viv.» y se deducen unas necesidades de 10.960 nuevas viviendas. En este caso, quizás también por la fecha de aprobación (2009), tras el inicio del declive inmobiliario, la Administración regional impuso una importante restricción a las propuestas de crecimiento, reduciéndola a 5.165 viviendas. Algo similar sucederá con otros municipios con aprobaciones posteriores ${ }^{27}$.

Aún más simple, en el Plan de Fresno de Torote, se justifica la clasificación de suelo en el que cabría cinco veces la población inicial por la «necesidad de continuar la búsqueda de un desarrollo urbano cerrado y compacto» ${ }^{28}$.

Pero tampoco es mejor la aportación técnica cuando parece prestársele mayor atención a la dinámica demográfica. En el Plan General de Ciempozuelos, hay apartados dedicados a hacer valoraciones y estimaciones sobre la estructura de la población, sobre la natalidad, la fecundidad y el reemplazo generacional. Se hacen unas "proyecciones de población» para el 2011 mediante un «ajuste exponencial» con la tasa media anual del periodo 1996-200129. Todo ello está sólo dirigido a justificar la necesidad de promocionar nuevos desarrollos. En el apartado «Planteamiento conceptual», se dice que Ciempozuelos tiene «amplias perspectivas de mantener los actuales índices de crecimiento en los próximos años [...] siempre y cuando el planeamiento no lo dificulte» ${ }^{30}$. Y en el apartado de las proyecciones de población, se dice: «[...] la variable independiente es el suelo residencial y la variable dependiente la población. Por eso parece razonable tomar en consideración las viviendas previstas [...] »31. Y nuevamente aparece el desarrollismo, el crecimiento demográfico como objetivo: «Las previsiones municipales son alcanzar a corto plazo los 20.000 habitantes y a más largo plazo, las previsiones apuntan a los 35.000 habitantes en 20 años, cifra a la que se puede llegar con una oferta suficiente de suelo calificado».

En Fuente el Saz, la valoración demográfica se reduce a la serie de datos de población de 1975 a 2008, que permite constatar su tendencia creciente, que se suaviza a partir de $2006^{32}$. Después se elabora un breve análisis de la evolución del tamaño de los hogares y de vivienda con datos del censo de 2001,

26. Memoria de ordenación, 5.2, p. 72-75.

27. Brunete, Ciempozuelos, Fuente El Saz, Meco y Móstoles experimentan recortes significativos en la previsión de viviendas, aunque en la mayoría de los casos no afecta a la superficie de suelo clasificada, sino a la edificabilidad permitida (ver acuerdos de aprobación).

28. Memoria justificativa, p. 2.

29. Documento de información urbanística, 3.2, p. 101-135.

30. Memoria descriptiva y justificativa, cap. 3, 3.2, p. 501.

31. Documento de información urbanística, 2.4.6, p. 154.

32. Memoria de información, 2, p. 28-34. 
pero no se hace mención alguna al importante volumen de viviendas edificado en el periodo 2001-2010. A partir de ahí, se llega al siguiente «diagnóstico»:

El futuro desarrollo de Fuente el Saz de Jarama pasa por capacitar al municipio para la recepción de importantes flujos migratorios que según todos los indicadores se producirá en los próximos años a consecuencia de la puesta en marcha del nuevo modelo territorial de la Comunidad de Madrid y de la evolución del propio proceso de reestructuración de la industria madrileña ${ }^{33}$.

En la memoria del plan, no hay constancia de los indicadores en los que se basa y tampoco se explica cual es ese "nuevo modelo territorial», pero se prevén 3.711 nuevas viviendas, lo que supone el deseo de multiplicar por tres la población existente en el momento de la aprobación, «[...] oportunidad que no debe desaprovecharse, puesto que aquellos municipios que no se incorporen a la estrategia urbanística regional, pueden verse relegados a un segundo plano» ${ }^{34}$. En la memoria justificativa, argumentan, además, «la necesidad de garantizar una suficiente fluidez del mercado del suelo, tanto para usos residenciales como industriales y productivos, que obliga a incorporar nuevas áreas de expansión de la ciudad ${ }^{35}$. Posteriormente, el Gobierno Regional, en el Acuerdo de Aprobación, aprueba exclusivamente dos de los seis sectores urbanizables presentados, aquellos con ordenación pormenorizada, con capacidad para 1.559 viviendas, argumentando afecciones ambientales y «número excesivo de viviendas" propuestas ${ }^{36}$.

En Getafe, el plan se propone como objetivo que la ciudad «tenga un crecimiento sostenible» ${ }^{37}$, dice que fundamenta sus determinaciones en el Plan Regional de Estrategia Territorial de Madrid (PRET), intento frustrado de ordenación territorial de la Comunidad de Madrid, del que sólo llegó a redactarse un documento de bases en 1995 (Valenzuela, 2010: 111), pero no respeta el techo de 150.000 habitantes que en él se fijaba y, en un alarde de incoherencia, clasifica suelo para $205.000^{38}$. También el PGOU de Paracuellos cuenta con un completo informe de las principales variables del análisis demográfico ${ }^{39}$, pero luego basa sus propuestas en las determinaciones del PRET.

El Plan de Móstoles presenta algunas singularidades. Se reconoce «un constante proceso de desaceleración del rimo demográfico $»^{40} \mathrm{y}$, tras un análisis detallado del parque de vivienda por barrios, se afirma que "la modestia socioeconómica de los ocupantes tiene su justo correlato en la modestia constructiva y dotacional de las viviendas. Ello da pie a la generación de una demanda de

33. Memoria de información, 3.5, p. 68.

34. Memoria justificativa, 1, p. 3.

35. Memoria justificativa, 1, p. 2.

36. Acuerdo de aprobación. BOCM, n.o 243, 13/10/2010, p. 82-83.

37. Memoria justificativa, p. 181.

38. Memoria justificativa, p. 218.

39. Memoria de información, p. 100.

40. Memoria resumen de la información, p. 84. 
mejora, correlativa a los procesos de movilidad social ascendente» ${ }^{41}$. El apartado «Proyecciones de población ${ }^{42}$ comienza señalando que la evolución demográfica es consecuencia de la "capacidad relativa de absorción de población que depende del número de viviendas ofertadas, su tipología, calidad y precio en relación con la del resto de municipios». No se dimensiona el suelo para nuevos desarrollos «en función de las expectativas de crecimiento demográfico de la ciudad en un periodo determinado de tiempo más o menos amplio». Por ello, «no se requiere realizar unas proyecciones de población a una fecha fija [...] sino describir una tendencia de evolución y evaluar los años de validez cuantitativa del modelo». Sin embargo, a continuación, sobre unas proyecciones realizadas por la Comunidad de Madrid y bajo el epígrafe «Proyección de las necesidades de viviendas", mediante un procedimiento simplificado del método de «jefatura de hogar», transforma la población en viviendas. Lo más relevante vuelve a ser la reiteración de la ambivalencia con respecto a las previsiones de población: primero se resta importancia a la dinámica demográfica que será consecuencia del número de viviendas que ofrezca el plan, pero termina recurriéndose a los resultados de las proyecciones para validar el modelo que propone 25.000 viviendas más en quince años.

En el caso de Rivas ${ }^{43}$, la memoria de información recoge un apartado dedicado a "Sociodemografía», en el que se incluyen los principales datos demográficos, para luego plantear un modelo de colmatación del municipio acorde con la «dinámica territorial» del entorno.

En las determinaciones de los planes analizados, así como en su desarrollo posterior, no hay en principio nada al margen de la normativa legal. Incluso en algunos se hace mención expresa al artículo 33.1.a de la Ley 9/2001, de Suelo de la Comunidad de Madrid, que establece que «La potestad de planeamiento de la ordenación urbanística se ejercerá observando las siguientes reglas: Operar a la vista de información suficiente sobre la realidad existente y sobre una valoración razonable de la previsible evolución de ésta [...]». Ello es compatible con que los «estudios técnicos» en los que teóricamente se sustenta el modelo de ciudad no son más que un conjunto de datos e informaciones generalmente insuficientes y no validados y siempre libremente interpretados, para llegar «necesariamente» a unas conclusiones previamente establecidas sobre la "conveniencia» de maximizar los desarrollos residenciales futuros. La aceptación de que se utilicen crecimientos exponenciales de la población total como único argumento técnico para justificar las necesidades de nuevas viviendas es la clara constatación de la más absoluta falta de rigor y de que las propuestas a favor del crecimiento urbano hasta la colmatación han adquirido valor axiomático.

Se han mencionado algunas imposiciones restrictivas por parte del Gobierno regional, que en todo caso no pasan de ser acciones puntuales de retoque para rebajar algunos excesos «excesivos» cuando ya había estallado la burbuja,

41. Memoria resumen de la información, p. 117.

42. Memoria de información, p. 133-140.

43. Memoria de ordenación, p. 25 y 32. 
pero que no debe interpretarse como un cambio de actitud en la filosofía urbanizadora ni de los gobiernos locales ni del Gobierno regional, a juzgar por las declaraciones y los intereses mostrados en los principales medios de comunicación. Las pocas voces que se oponen son de grupos ecologistas y generalmente lo hacen para denunciar afecciones medioambientales. La Federación Regional de Asociaciones de Vecinos de Madrid, con una perspectiva más amplia, también ha rebatido el modelo defendiendo «la austeridad urbanística [...] la prioridad de la actuación sobre el espacio urbano consolidado, antes que las políticas depredadoras de colonización del territorio [...]» dentro de «[...] una estrategia más amplia y superior de supervivencia del medio ambiente» (FRAVM, 2005).

Pero no hay respuestas con contenido técnico que descalifiquen tales crecimientos por su inviabilidad territorial, social y demográfica. Ni el territorio ni el crecimiento de la población son ilimitados, cosa que parece deducirse de muchas propuestas de crecimiento, y al planeamiento hay que exigirle coherencia en las interacciones entre población y territorio que se derivan de sus propuestas y de las que van a depender la cohesión social y la calidad de vida. La ausencia de rigor en el análisis territorial y de coherencia en el discurso argumental entre el diagnóstico técnico y la validación de las propuestas facilitan que la planificación urbanística acabe siendo exactamente lo contrario de lo que debería ser. La recuperación de la racionalidad en los modelos de desarrollo urbano, que induzca a aplicar soluciones menos consumistas en términos energéticos y de ocupación territorial y más acordes con la realidad sociodemográfica, exige que el planeamiento se dote realmente de rigor técnico y científico y que se vea requerido en la tramitación de su aprobación a superar pruebas de coherencia territorial bajo criterios e indicadores normalizados y comúnmente aceptados (Galiana y Vinuesa, 20IO: 13I).

\section{Consecuencias territoriales de la sobredimensión}

El haber construido muchas más viviendas de las realmente necesarias, además de ser un grave problema para la economía española (Romero, 2010: 23), tiene nefastas consecuencias territoriales, urbanísticas y sociales. La producción inmobiliaria, que ha visto crecer su peso en la economía nacional a lo largo de los últimos cincuenta años, ha vivido, desde la segunda mitad de los años noventa, en un contexto neoliberal, una etapa de absoluto desenfreno impulsada por un sector financiero tan ajeno a los valores territoriales y a la calidad urbanística, como determinante en las consecuencias de su materialización (Gaja, 2008: 109; Romero, 2010: 31).

Para el mundo del dinero y de los grandes y rápidos beneficios, la producción de espacio urbano, de viviendas, no es un objetivo en sí mismo. Es simplemente un medio. Los resultados territoriales, lo que «le está pasando al territorio», en palabras de Onofre Rullán (2011b), no son más que efectos secundarios que están siendo mal valorados por la sociedad en su conjunto. Desde los poderes públicos hasta los ciudadanos, pasando por financieros, 
inmobiliarias, constructoras..., todos ven en el desarrollo urbano la oportunidad de comerciar con el suelo, con la vivienda, para obtener fácilmente pingües plusvalías. Todo lo relativo a la transformación del territorio, a la construcción de la ciudad, como escenario en el que debe concretarse en buena medida la calidad de vida de las generaciones actuales y futuras, queda en un segundo plano y siempre supeditado al interés económico a corto plazo.

Dentro de ese juego de intereses, el planeamiento urbanístico, que en teoría es una herramienta al servicio de la intervención pública en defensa de la racionalidad en la utilización del suelo de acuerdo con el interés general, en favor de la equidad y de la cohesión social y para impedir la especulación, ha ido degradando su naturaleza hasta convertirse en el respaldo técnico de la irracionalidad territorial y en la legitimación de aquello que debería combatir.

¿Cómo explicar la actual situación de los balances de los bancos, hinchados en la creencia de que la ficción de planificar y acometer desarrollos residenciales diez o veinte veces por encima de lo razonable se podrían convertir en una realidad perdurable, al menos en sus efectos sobre los precios del suelo, que, por un mecanismo de contagio, se traslada a los de las viviendas, que también son suelo? El respaldo planificador ha permitido enormes incrementos en los precios del suelo, pero cuando el motor financiero se para, el juego se interrumpe bruscamente, la demanda desaparece y los precios y los balances no se sostienen. En los días en los que se escribe este artículo, todavía se debate sobre la creación de un «banco malo». Los titulares de los periódicos, las declaraciones de los expertos y de los políticos sólo giran en torno a cómo solucionar el desaguisado económico y cómo «remontar el vuelo».

Dada la naturaleza del juego financiero, es fácil entender que el "cuanto más y más rápido, mejor» actúe como una regla básica; que la evidencia de que el territorio es un bien necesario y limitado solo atañe a la cuantificación de su capacidad máxima, y que se desprecien por irrelevantes los efectos perversos sobre el territorio y sobre la calidad del espacio urbano. A pesar de que son generalmente invocados los criterios de sostenibilidad, lo cierto es que la idea de que sólo debería transformarse el territorio estrictamente necesario cercena las expectativas de enriquecimiento a corto plazo y, por tanto, no se respeta. Por el contrario, lo que predomina, con el aliento del «todo urbanizable», es la voluntad de extraer al máximo las plusvalías lo más rápidamente posible, con la premura de no quedar rezagados en esa "carrera». Y es la prevalencia de esos intereses lo que conduce a que el planeamiento urbanístico de muchos municipios haya clasificado para futuros desarrollos mucho más suelo del que razonablemente se podrá necesitar, por muy lejos que nos queramos ir en el tiempo. En los casos en que no se han producido desarrollos, urbanizaciones o construcciones, tal clasificación supone un compromiso con los agentes económicos y una grave dificultad para intentar restaurar la racionalidad territorial.

Peores, evidentemente, son las consecuencias territoriales cuando se han urbanizado suelos sin utilización previsible y queda un paisaje desfigurado por unas infraestructuras condenadas al deterioro producido por el paso del tiempo 


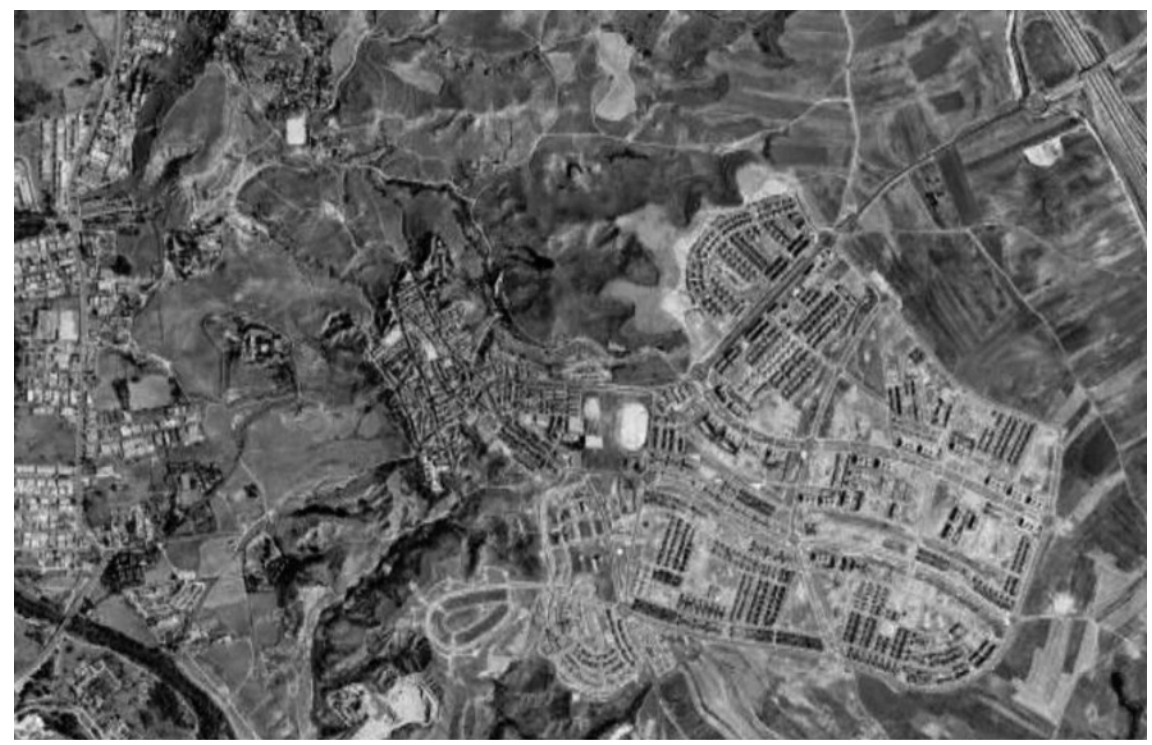

Figura 2. Cuando lo urbanizado es la negación de lo urbano. En Paracuellos del Jarama, miles de viviendas en espacio urbanizado pero no urbano: espacios residenciales de baja densidad, ineficientes, que buscan eliminar la diversidad y la pluralidad social y favorecen el aislamiento y la segregación. ¿Quién y cuándo va a dotar los equipamientos?

Fuente: GoogleEarth.

y la ausencia de mantenimiento, cuya única «utilidad» para el interés general habrá sido su impacto innecesario.

Pero este modelo de desarrollo urbano a ultranza no sólo es pernicioso por un innecesario consumo de territorio. En los casos en los que se lleguen a consumar los excesos con la construcción de las viviendas previstas, normalmente el resultado físico será de grandes superficies de espacio residencial, de aparente calidad constructiva, pero que no tendrán, en muchos años o quizás nunca, carácter de auténtico espacio urbano. Tanto en el improbable caso de que se poblaran rápidamente como cuando su ocupación se produce muy lentamente, será prácticamente imposible alcanzar una mínima urdimbre social. Son nuevos espacios periféricos, cuando no aislados de los núcleos tradicionales, generalmente de bajas densidades, que imponen unos modelos de movilidad dependientes del uso del automóvil privado y que podrían quebrar, económica y funcionalmente, con un eventual encarecimiento del precio de la energía.

¿Qué decir del despilfarro territorial, económico y social que suponen seis millones de viviendas desocupadas (Vinuesa et al., 2008; Martínez, 2012), escandalosa y estúpida situación que el planeamiento expansivo, en lugar de corregir, se ha ocupado de agravar?

¿Cómo valorar los enormes costes sociales derivados de los déficits de calidad de vida urbana (carencias de equipamientos, altas proporciones de vivien- 


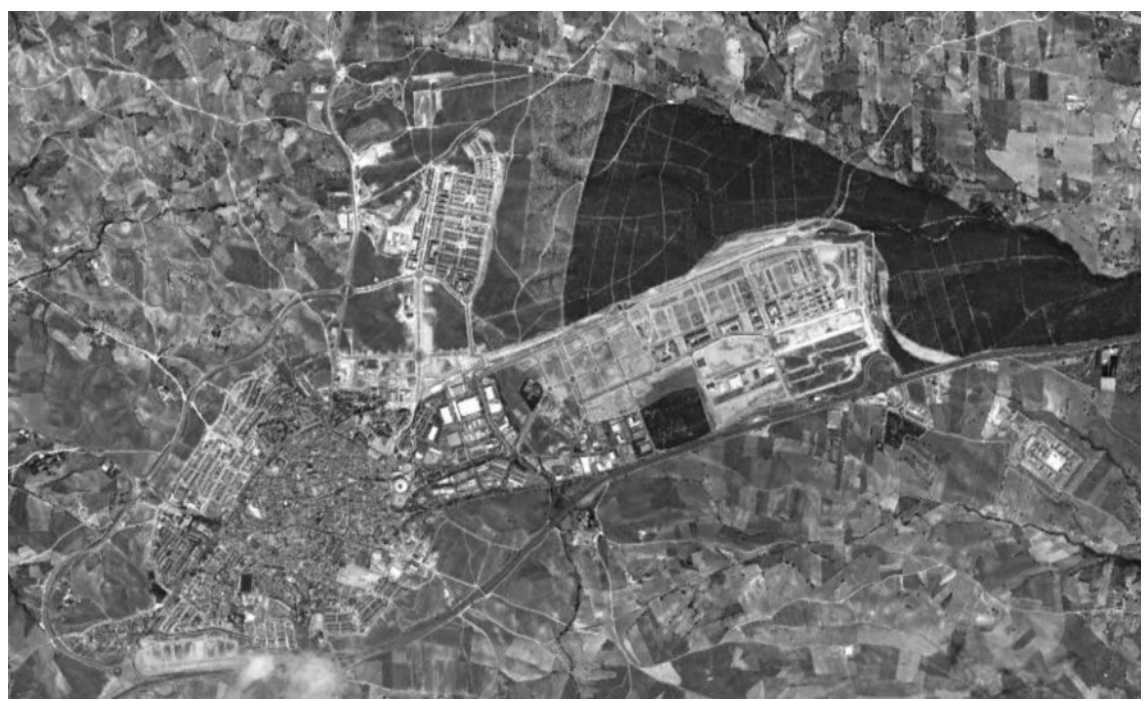

Figura 3. Navalcarnero. Territorio urbanizado y vacio. ¿Se podrá impedir su progresivo deterioro? ¿Se ocupará alguna vez?

Fuente: GoogleEarth.

das vacías, debilidad de la cohesión social, ausencia de animación urbana, etc.) de todos esos espacios que quizás no se consoliden nunca, aunque hayan recibido «licencias de primera ocupación»? ¿Cómo van a poder las haciendas locales atender los enormes gastos brutos y por residente derivados de esos nuevos y sobredimensionados desarrollos?

\section{Y ahora, ¿qué se puede hacer?}

Los trabajos publicados en los últimos años, de los que la bibliografía aquí citada es una buena representación, coinciden básicamente en las valoraciones del proceso y en sus diagnósticos. Especialmente los elaborados por geógrafos presentan análisis globalizadores en los que se describen los efectos producidos sobre diversos aspectos económicos, sociales y territoriales, poniendo de manifiesto también los factores desencadenantes. En algunos casos, se proponen los cambios que se habrían de afrontar para abandonar el irracional e insostenible modelo actual, pero existe el riesgo de que lo aparatoso de algunos efectos impida ver las auténticas causas.

Ahora, cuando el desastre es evidente y en buena medida irreversible, las denuncias son la norma, y no sólo desde los ámbitos académicos, sino también desde las tribunas políticas, e incluso no faltan los lamentos de algunos de los actores directos y principales causantes de los desafueros. Pero no debe perderse la perspectiva. Lo que produce los lamentos es «la crisis», que básicamente consiste en que ahora no se puede seguir haciendo lo que se ha hecho en la 
«época de bonanza». Por eso son muy oportunas las palabras de Juan Romero (2010: 42) cuando escribe: «Sobra retórica. Pero falta cultura y voluntad política para adentrarnos en el camino de la buena gobernanza democrática y del buen gobierno del territorio".

La clave de todo está en las ingentes plusvalías que se pueden generar con el proceso planificador y en su reparto. Las especiales características del mercado del suelo, que facilitan las estrategias de acumulación y de especulación, ayudan a crear un contexto en el que cualquier propuesta queda postergada ante la posibilidad de maximizar esas plusvalías. Las posibles decisiones de los poderes públicos para dar racionalidad al desarrollo urbano, con criterios de equidad, cohesión social y sostenibilidad, se entenderían como contrarias a esas propuestas maximalistas de generación de «riqueza» y empleo y no serían bien recibidas por una sociedad que no tiene la suficiente cultura urbanística, que no parece tener plenamente asimilada la idea de la función social de la propiedad (art. 33.2 CE), ni la prevalencia de los intereses generales sobre los particulares, ni de la exigencia de evitar la especulación y de que ha de haber un reparto equitativo de las plusvalías (art. $47 \mathrm{CE}$ ). Una sociedad que permanece indiferente ante la corrupción urbanística, que sería la anécdota, e impasible ante la "corrupción del urbanismo» (Gaja, 2007), que ha dejado de ser una garantía de racionalidad territorial para convertirse en un instrumento al servicio de los intereses económicos. Una sociedad que no parece ser consciente de que el territorio es un bien necesario, con valor — no precio- por sí mismo, limitado y no siempre recuperable, que debe ser utilizado con criterios de austeridad y racionalidad.

Sean bienvenidas todas las denuncias de deficiencias normativas y de malas prácticas, así como todas las propuestas para corregir las perversiones del modelo de desarrollo urbano y para paliar sus efectos (Fariña y Naredo, 2010: 27). Efectivamente, no habrá racionalidad si no hay coordinación y cooperación entre las diferentes administraciones y de estas con todos los agentes sociales y con los ciudadanos (Valenzuela, 2010: 123). No habrá racionalidad en el planeamiento si este no se elabora a partir de unas directrices territoriales, de carácter supralocal. ¿Puede mantenerse la discrecionalidad de la visión exclusivamente local en un territorio dividido en más de 8.100 municipios? Habrá que seguir debatiendo sobre el papel del urbanismo como gran generador de recursos para las haciendas locales (Romero, 2010: 35) y, consecuentemente, sobre la incidencia de esa realidad en la corrupción urbanística y del planeamiento. Pero, pudiendo contribuir todo eso al cambio, parece evidente que no tendremos otro modelo hasta que la sociedad sepa valorar la conveniencia de la existencia de un planeamiento elaborado a partir de criterios de racionalidad territorial.

Lo que ha ocurrido no es una catástrofe natural ni tiene su origen en lejanos enclaves de poder económico, es sobre todo el resultado de la voluntad de una sociedad que, careciendo de la cultura urbanística y territorial necesarias para valorar adecuadamente el proceso, se deja llevar por las fascinantes propuestas del enriquecimiento rápido y fácil en que se fundamenta el modelo de desarrollo urbano imperante. 
No tiene sentido invocar la racionalidad territorial si previamente no se defiende y se difunde el conocimiento, si no se exige que la planificación se fundamente en análisis rigurosos de la dinámica territorial. En este trabajo, a modo de ejemplo probatorio, se ha podido constatar el desprecio por un conocimiento riguroso de la dinámica demográfica como elemento estructurante del desarrollo urbano. Es en la falta de rigor del análisis territorial donde se inicia la perversión de la naturaleza del planeamiento urbanístico.

Parece imprescindible establecer un nuevo marco legislativo que garantice el control del rigor técnico y la racionalidad de las propuestas del planeamiento, aparte de la cuestionada evaluación ambiental estratégica de planes y programas ${ }^{44}$. También habrá que hacer seguimiento mediante observatorios territoriales y urbanos (Servert, 2012: 20) que habrán de actuar, con o sin carácter operativo, como organismos independientes, garantes de la racionalidad y de la defensa de los principios que, de acuerdo con las leyes, deberían regir la actuación de un planeamiento urbanístico regenerado al servicio del interés general y en defensa del territorio.

Sin que suponga menoscabo para otras muchas reformas necesarias, la mejora técnica del planeamiento es quizás la principal reivindicación que debe hacerse desde la academia y desde la ética profesional, por ello, la propuesta va especialmente dirigida a quienes puedan aportar conocimiento y difundirlo.

\section{Referencias bibliográficas}

BRANDIs, Dolores (2008). «Los grandes desarrollos residenciales de la periferia de Madrid: De la burbuja a la crisis inmobiliaria». En: Delgado, C. (ed.). Espacios y paisajes urbanos: Reflexionar sobre su presente para proyectar su futuro [en línea], p. 1-18. <http://www.uib.es/ggu/cd2/1\%20Ponencia/Brandis\%20Garcia,\%20 Dolores.pdf> [Consulta: diciembre 2011].

BURRIEL, Eugenio (2002). «Análisis geodemográfico y planificación territorial en España». Estudios Geográficos, LXIII, 248-249, 443-469.

- (2003). «La demografía en la planificación territorial». Eria, 60, 93-103.

- (2008). «La "década prodigiosa" del urbanismo español (1997-2006)». Scripta Nova: Revista Electrónica de Geografía y Ciencias Sociales [en línea]. Barcelona: Universidad de Barcelona, 1 de agosto de 2008, vol. xII, núm. 270 (64). <http:// www.ub.es/geocrit/sn/sn-270/sn-270/sn-270-64.htm>.

Consejería de Medio Ambiente y Ordenación del Territorio de la Comunidad DE MADRID. <http://wwww.madrid.org/cartografia/planea/planeamiento/html/web/ visorplaneamiento.htm> [Consulta: diciembre 2011].

FRAVM (2005). Alegaciones al Anteproyecto de Ley del Suelo de la Comunidad de Madrid de 19 de octubre de 2005 [en línea]. <http://aavvmadrid.org/index.php/ content/view/full/1412> [Consulta: diciembre 2011].

GAJA, Fernando (2007). ¿Corrupción urbanistica o corrupción del urbanismo? [en línea] $<$ http://www.levante-emv.com/opinion/3403/corrupcion-urbanistica-o-corrupcion-urbanismo/263378.html> [Consulta: enero 2012].

44. Traspuesta al sistema legislativo estatal a través de la Ley 9/2006 que traspone la Directiva 2001/42/CE. 
- (2008). «Urbanismo ecológico, ¿sueño o pesadilla?». Revista Internacional de Sostenibilidad, Tecnología y Humanismo, 3, I05-I26.

Galiana, L. y Vinuesa, J. (coord.) (20IO). Teoría y práctica para una ordenación racional del territorio. Madrid: Síntesis, $346 \mathrm{p}$.

Fariña, J. y Naredo, J. M. (dirs.) (2010). Libro Blanco de la sostenibilidad en el planeamiento urbanístico español. Madrid: Centro de Publicaciones de la Secretaría General Técnica. Ministerio de la Vivienda del Gobierno Español.

INE (2011). Proyecciones de Población a corto plazo. Últimos datos publicados: serie 2011-2021 [en línea] (7 octubre 2011). <http://www.ine.es> [Consulta: diciembre 2011].

Martín, Blanca (2009). Análisis geográfico en el planeamiento urbanístico: Propuesta metodológica para la elaboración de estudios de análisis y diagnóstico territorial para planes urbanísticos [en línea]. <http://biblioteca.uam.es/sc/BibloseArchivo .html>.

- (2012). "Análisis territorial y planeamiento". Ciudad y Territorio: Estudios Territoriales, 172 (en prensa).

Martínez, J. M. (2012). En España un 20\% de las viviendas están vacías. En una década las casas desocupadas pueden pasar de los 3,1 a los seis millones [en línea]. <http://www.elpais.com/articulo/economia/Espana/viviendas/estan/vacias/ elpepueco/20120105elpepueco_6/Tes> [Consulta: enero 2012].

Mata, Rafael (2008). Auge inmobiliario y evolución de los usos del suelo en España. Por una nueva cultura del territorio: Lección inaugural del Curso Académico 2007-2008. Madrid: Universidad Autónoma de Madrid, 70.

Ministerio de Fomento (2012). <http://www.fomento.gob.es/BE2/?nivel=2\&orden $=33000000>$ [Consulta: enero 2012].

Módenes Cabrerizo, Juan Antonio (2010). «Una mirada demogràfica als canvis recents en l'accés a l'habitage a Catalunya». Treballs de la Societat Catalana de Geografía, 69, 113-140.

Naredo, José Manuel (2010). El modelo inmobiliario español y sus consecuencias [en línea]. Madrid, marzo. <http://habitat.aq.upm.es/boletin/n44/ajnar.html>.

Naredo, José Manuel; Carpintero, Óscar y Marcos, Carmen (2008). Patrimonio inmobiliario y balance nacional de la economía española (1995-2007). Madrid: Funcas.

Reques, Pedro y Cos, Olga de (2003). "Geodemografía y planificación estratégica en Cantabria: De la escala local a la regional». En: La dinámica demográfica protagonista del territorio. Actas del VIII Congreso de la Población Española. Santiago de Compostela. Universidad de Santiago de Compostela, 219-233.

Romero, Juan (2010). «Construcción residencial y gobierno del territorio en España. De la burbuja especulativa a la recesión. Causas y consecuencias». Cuadernos Geográficos, 47 (2), 17-46.

Rullán, Onofre y Artigues, Antoni A. (2007). «Estrategias para combatir el encarecimiento de la vivienda en España. ¿Construir más o intervenir en el parque existente?». Scripta Nova: Revista Electrónica de Geografía y Ciencias Sociales [en línea]. Barcelona: Universidad de Barcelona, vol. xI, núm. 245 (28). <http://www. ub.es/geocrit/sn/sn-24528.htm>.

Rullán, Onofre (2011a). «La regulación del crecimiento urbanístico en el litoral mediterráneo español». Ciudady Territorio: Estudios Territoriales, XLIII (168), 279-297.

- (2011b). ¿Qué le está pasando al territorio? [en línea]. Asociación de Geógrafos Españoles. <http://age.ieg.csic.es/v2/index.php?m=actualidad> [Consulta: noviembre 2011]. 
Servert, Raoul (2012). «Crónica de una decepción: El fracaso de los informes de sostenibilidad ambiental y las memorias ambientales en la evaluación ambiental estratégica del planeamiento urbanístico». Cuadernos de Ordenación del Territorio. FUNDICOT, V época (2), 15-20.

VALENZuela, Manuel (2010). «La planificación territorial de la región metropolitana de Madrid: Una asignatura pendiente». Cuadernos Geográficos, 47 (2), 95-129.

VinUESA, Julio (1995). «Análisis geodemográfico y planeamiento urbanístico». Estudios Geográficos, LVI, 219, 147-168.

- (2003). «Población y demanda de vivienda: una relación a reconsiderar». En: La dinámica demográfica protagonista del territorio. Actas del VIII Congreso de la Población Española. Santiago de Compostela: Universidad de Santiago de Compostela, 283-290.

- (2005). «Dinámica demográfica, vivienda y territorio». Papeles de Economía Española, 104, 253-269.

- (2008). "La vivienda vacía en España: un despilfarro social y territorial insostenible». Scripta Nova: Revista Electrónica de Geografía y Ciencias Sociales [en línea]. Barcelona: Universidad de Barcelona, 1 de agosto de 2008, XII, 270 (39). <http:// www.ub.es/geocrit/sn/sn-270/sn-270-39.htm>.

Vinuesa, Julio; Riva, José María de la y Palacios, Antonio (2008). El fenómeno de las viviendas desocupadas [en línea]. Madrid. <http://www.uam.es/personal_pdi/ filoyletras/ juvian/ publicaciones.htm> [Consulta: enero 2012]. 